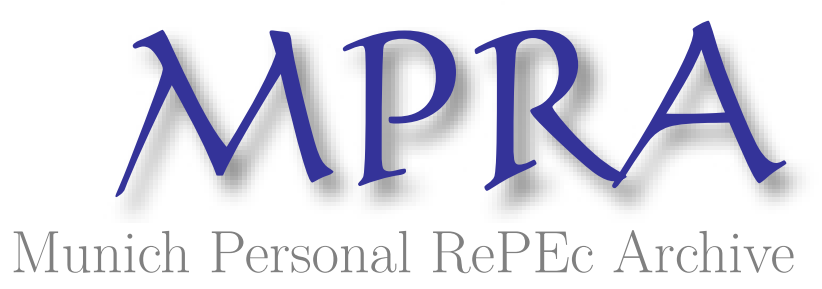

Over-education for the rich, under-education for the poor: a search-theoretic microfoundation

Charlot, Olivier and Decreuse, Bruno

GREQAM

2006

Online at https://mpra.ub.uni-muenchen.de/3624/

MPRA Paper No. 3624, posted 19 Jun 2007 UTC 


\title{
Over-education for the rich, under-education for the poor: a search-theoretic microfoundation*
}

\author{
Olivier CHARLOT \\ LIBRE, Université de Franche-Comté ${ }^{\dagger}$ \\ Bruno DECREUSE \\ GREQAM, Université de la Méditerranée ${ }^{\ddagger}$
}

April 2007

Abstract: This paper studies the efficiency of educational choices in a two sector/two schooling level matching model of the labour market where a continuum of heterogenous workers allocates itself between sectors depending on their decision to invest in education. Individuals differ in ability and schooling cost, the search market is segmented by education, and there is free entry of new firms in each sector. Self-selection in education originates composition effects in the distribution of skills across sectors. This in turn modifies the intensity of job creation, implying the private and social returns to schooling always differ. Provided that ability and schooling cost are not too positively correlated, agents with large schooling costs the 'poor' - select themselves too much, while there is too little self-selection among the low schooling cost individuals - the 'rich'. We also show that education should be more taxed than subsidized when the Hosios condition holds.

Keywords: Ability; Schooling cost; Heterogeneity; Matching frictions; Efficiency

J.E.L. classification: I20, J21, J60

\footnotetext{
${ }^{*}$ We thank Antoine d'Autume, Pierre Cahuc, Etienne Lehmann, Bertrand Wigniolle, participants to the conferences of the European Economic Association 2004, French Economic Association 2004, Public Economic Theory 2005 and participants to seminars at EUREQUA, GREQAM, CIRPEE and LAMETA for useful comments. The usual disclaimer applies.

${ }^{\dagger}$ LIBRE et Université de Franche-Comté, UFR SJEPG, 45D Avenue de l'observatoire, 25030 Besançon Cedex, France. E-mail: ocharlot@univ-fcomte.fr

${ }^{\ddagger}$ GREQAM - 2, rue de la charité, 13236 Marseille cedex 02, France. E-mail: decreuse@univmed.fr
} 


\section{Introduction}

It is well-known that self-selection in education gives rise to composition effects in the distribution of skills across education groups. Namely, self-selection implies that the characteristics of the agents who educate generally differ from the characteristics of those who do not. In a competitive labour market, such composition effects shape within and between-group wage dispersion. However, they do not alter the efficiency of educational choices. This property does not hold in a frictional labour market, where composition effects may distort the incentives to schooling. In a model where agents only differ with respect to labour market ability, Charlot and Decreuse (2005) show that self-selection in education is inefficient, and too many workers are willing to acquire education. The purpose of the present paper is to reconsider their result in the realistic case where agents not only differ in labour market ability, but also in schooling cost. Our main conclusion is that provided ability and schooling cost are not too positively correlated, agents with large schooling costs - the 'poor' - select themselves too much, while there is too little self-selection among the low schooling cost individuals - the 'rich'. We also study the combination of labour market and education policy that decentralizes the efficient allocation. There, we suggest that education should be more taxed than subsidized.

Our model is based on three main features. First, there is worker-job heterogeneity. There are two schooling levels, educated/uneducated, and two production sectors, one for the high-skill (complex) jobs, and the other for the low-skill (simple) jobs. There are two sources of heterogeneity among workers : ability and schooling costs. This assumption is the major departure from our previous contribution (Charlot and Decreuse, 2005). We shall refer to agents endowed with low schooling costs as the 'rich', and to those with high schooling costs as the 'poor' . Second, we consider a frictional labour market. The number of contacts between employers and job-seekers is driven by a constant returns to scale matching technology. The search market is fully segmented by education/technology, but not by ability: only the educated can do the high-skill jobs, and firms target their high-skill positions towards the educated. Wages are determined by Nash bargaining, and sectorial job creation is endogenized by means of a free entry condition. Free entry implies sectorial job creation depends on the composition of education groups. Third, there is self-selection in education. Agents face a binary schooling choice, i.e. being educated or uneducated, and select themselves on the basis of their private costs and returns to schooling. Only those whose ability is sufficiently high and/or whose schooling cost is sufficiently low choose to invest in education. At individual level, self-selection depends on market factors, as productivity differences ${ }^{2}$ and unemployment rate differences across

\footnotetext{
${ }^{1}$ This is of course a short-cut as we consider a non-degenerate joint distribution of characteristics.

${ }^{2}$ As in Roy's (1951) model of job assignment.
} 
sectors $^{3}$.

In a frictionless (walrasian) environment, a worker's return to education depends on her own innate characteristics and on sectorial productivity differences, but it is not altered by the composition of education groups. Educational choices are therefore efficient. In a frictional economy, the composition of education groups alters wage and employment opportunities, and, in turn, self-selection is driven by sectorial wage and employment differences. As a result, educational choices are generally inefficient.

Namely, wage and employment opportunities depend on the intensity of job creation, and under free entry, job creation in each sector depends on the average labour market ability across the pool of job-seekers ${ }^{4}$. Anyone whose ability is above (below) the sector-specific mean ability generates a positive (negative) sector-specific externality by boosting (reducing) job creation, and therefore driving wage and employment opportunities upwards (downwards). Hence, high-ability individuals under-estimate the return to schooling, while the less able over-estimate it. Provided that schooling cost and ability are not too positively correlated, agents who face large schooling costs - the poor - select themselves too much, while those who face small schooling costs - the rich - select themselves too little. Hence, search frictions provide a rationale to the following claim: there are too many rich investing in education, which depreciates the return to schooling, and crowds out poorer and abler individuals from schooling.

Incidentally, congestion externalities may alter this general reasoning, so that overeducation may prevail at all schooling costs. Assume individuals only differ in their schooling costs. In this case, the private return to participation in a given sector is lower than the social return unless the so-called Hosios condition - that is, workers' bargaining power must be equal to the elasticity of the matching function with respect to the pool of unemployed - holds. If the difference between private and social return to participation is much smaller in the high-skill sector than in the low-skill one, then the private return to schooling exceeds the social return.

Finally, we turn to education policy. We assume the planner only observes individual schooling costs, and not ability. Efficiency requires that some of the high ability individuals with high schooling costs must be attracted in education, while some of the low ability individuals with low schooling costs must be deterred from education. This can be done with two instruments: a subsidy increasing in schooling costs, combined with

\footnotetext{
${ }^{3}$ This is a straightforward consequence of the incorporation of search frictions in a Roy-type economy.

${ }^{4}$ This latter property is due to rent-sharing, which implies that the profitability of a filled job raises with the worker's ability. There is considerable empirical evidence showing that wages are positively correlated with profitability. For instance, using a matched panel to control for worker as well as firm heterogeneity, Abowd, Kramarz and Margolis (1999) demonstrate that high skill workers are paid more and that profitability is higher for firms with more skilled workers.
} 
a lump-sum tuition cost. The optimal policy is therefore redistributive, as the 'poor' are more subsidized than they are taxed while the 'rich' are more taxed than subsidized. Given that, a natural question is thus: should education be taxed more than it should be subsidized? We answer this question in the particular case where the Hosios condition holds. Then, education must be taxed more than subsidized. The positive externalities induced by educational choices are more than outweighed by the negative externalities in this setting.

Our analysis is based on the existence of composition externalities induced by selfselection in education. Sorting models of education (such as those surveyed in Fernandez, 2001) also provide a number of examples where the composition of education groups matters for efficiency, though for different reasons. At the family level, there can be marital sorting influencing the way in which human capital and other abilities are intergenerationally transmitted. In the schooling system, there can be some peer effects involved. At production level, there are some complementarities between workers of different skill levels which may not be internalized within firms. In the city, the composition of the neighbourhood induces some important externalities through taxation and the provision of schooling. Closest to us, Fershtman, Murphy and Weiss (1996) build a model in which agents also differ in ability and schooling cost ("nonwage income" in their terminology). Beyond the access to high-skill/best-paid positions, education also provides the workers with social status. In their view, the demand for social status increases with the average ability of the high-skill workers. This entails a composition externality, so that the "wrong" individuals may be led to acquire schooling. In this perspective, the novelty of our paper is to exhibit a different yet realistic channel through which composition effects can be held responsible for the crowding-out from schooling of the poor by the rich.

The search literature emphasizes other reasons for inefficient educational investments. Acemoglu (1996) shows that rent sharing may translate into a hold-up problem for the workers. In models where there is a unique search market for all skill levels, Laing, Palivos and Wang (1995), and Burdett and Smith (2002) demonstrate that there are social increasing returns to schooling. This externality does not arise in our paper as the search market is segmented by education. There are also papers in this field highlighting overeducation as a potential outcome. In Snower (1995) and Saint-Paul (1996), there may be some excess supply of skills as a rise in the number of educated alters firms' incentives to allocate their vacancies between sectors. Moen (1999) considers a model where investing in education improves one's ranking in the job queue, but at the expense of the others. In the multi-dimensional skill model of Charlot, Decreuse and Granier (2005), workers invest in education to improve their chance of being employed, but also to raise their outside opportunities during the wage bargain. 
Our paper highlights a case of 'market adverse selection'. As the return to participation in each sector depends on sector-specific mean ability, all the agents tend to be attracted by the sector where the mean ability is the highest. At the market level, the ablest workers provide their less talented co-workers with wage and employment subsidies ${ }^{5}$. This situation occurs mainly because the market is segmented by education levels and not by ability. To appreciate the restrictiveness of such assumptions, it is worth investigating two polar cases.

On the one hand, the search market may be totally unsegmented. An externality similar to that highlighted by Burdett and Smith (2002) would then be at work. Increasing the share of educated individuals would raise the probability of meeting such workers; high-skill vacancies would then become more profitable for this reason; this would boost job creation. Such an externality would lead to under-education. In our paper, the search market is segmented by job type, as the uneducated cannot perform on the high skill jobs - a technological restriction. The above mentioned externality cannot arise, because each worker who gets an education also gets the right to participate to the market for high skill jobs.

On the other hand, the search market may be fully segmented, that is both by schooling level and by ability. The composition of education groups does not alter the schooling return in such a case, as individuals are homogenous within each cell of the search market. Of course, this is no longer the case in our contribution, because the low ability workers benefit from the presence of abler individuals in their market segment. Full segmentation is not a stable outcome in our setting, because of the adverse selection phenomena discussed above. Low ability workers have incentives to participate to the market segments where wage and employment opportunities are expected to be better ${ }^{6}$.

The paper is organized as follows: section 2 presents the basic setup. Section 3 studies the properties of the walrasian environment, whereas section 4 considers a frictional labour market. Section 5 deals with the design of the efficient policy. Section 6 concludes.

\footnotetext{
${ }^{5}$ In signalling models (see Arrow, 1973, and Spence, 1973), high ability workers also provide a wage subsidy to low ability workers, but at the firm level. In our paper, firms perfectly observe individual characteristics at the recruitment stage, and could reject an application to wait for a better match. In this perspective, the inefficiency of the decentralized allocation is due to employers' failure at the sector level to coordinate on the rejection of low ability workers' applications. Of course, this depends on the organization of the search market as we argue below.

${ }^{6}$ This is also due to the way wages are set in our paper, i.e. to rent-sharing. In the two ability level matching model of Inderst (2005), firms set wages and make them contingent on workers' ability. Then the search market partitions into two market segments. Our paper adopts the view that such contracts are not enforceable, either because ability is not observable (or at least not verifiable) by a court, or because workers have some market power. In the former case, Inderst shows that the search market is no longer segmented (see also the model of Lang and Manove, 2003, with continuous types).
} 


\section{The model}

\subsection{Environment}

Time is continuous. At each instant, $\delta>0$ agents are born. This ensures new cohorts enter the population and make their education decision at each instant. Agents are risk neutral, discount time at rate $\rho$, and have a constant risk of dying (retirement) $\delta>0$. Hence, the effective rate of discount is $r \equiv \rho+\delta$, and the global population is normalized to 1 .

Heterogeneity and education. There are two schooling levels: educated/uneducated. Agents are heterogenous with respect to two innate characteristics: schooling cost $c$ and labour market ability a (ability, for short). Those who pay the schooling cost get an education; those who do not remain uneducated. Heterogenous schooling costs may either reflect the existence of credit constraints, or different aptitudes to learn at school. Though we are aware these two interpretations may actually lead to drastically different policy recommendations, it is important at this stage to notice our results are derived under the assumption private and social schooling costs coincide. The externalities we point out are therefore independent of the standard market failure originating from credit market imperfections ${ }^{7}$. In the same way, heterogenous abilities may be attributed to different innate productive capacities, as well as to different social backgrounds. Schooling costs and ability are distributed across individuals within cohorts according to the stationary joint distribution $\phi: \mathbb{R}_{+} \rightarrow \mathbb{R}_{+}$.

Assumption 1 (i) The function $\phi$ is positive and continuous over $\mathbb{R}_{+} \times \mathbb{R}_{+}$

(ii) $\mathbb{E}(a)=\int_{c} \int_{a} \phi(a, c) a d a d c<+\infty$

We shall impose additional constraints later on, while examining the market and centralized outcomes in the frictional environment.

Production technologies. There are two sectors producing a single final good: a highskill, high productivity sector where complex tasks are performed and a low-skill, low productivity sector where simple tasks are performed. Sectors are indexed by $i=h, l$, where $h$ refers to the high-skill sector, and $l$ to the low-skill sector. Only the educated workers can do the high-skill jobs. In each sector, there is an endogenous mass of firms all endowed with a single job, which can be either vacant, or filled. As in the standard model (see Pissarides, 2000), holding a vacancy involves a flow cost $\gamma>0$.

\footnotetext{
${ }^{7}$ In section 5 where we deal with policy issues, it is explicitly assumed that there are no credit constraints.
} 
Output depends on firm's and worker's characteristics. Denoting by $y_{i a}$ the output of a type $a$ worker in a sector $i$ job, we have

$$
y_{i a}=A_{i} a
$$

where $A_{i}$ is a sector-specific productivity parameter, $A_{h}>A_{l}>0$. Complex jobs are thus more productive than simple jobs. This implies education has a productive role: it allows the workers to perform on more complex and more productive technologies. Note there is no peer-effect at the production stage: the ability of other workers does not affect one's productivity.

Matching sector. The search market is segmented by sector. Each individual is allowed to participate to either one of the two sectors, but not to both. In each sector, unemployed and vacancies are brought together by pair according to a constant-returns to scale (CRS) matching technology. The flow of (sectorial) matches $M_{i}$ between unemployed and vacancies is given by:

$$
M_{i} \equiv m_{0} M\left(u_{i}, v_{i}\right)
$$

with $m_{0}>0$ a scale parameter reflecting the magnitude of search frictions. Matching is random: matches are equiprobably distributed between unemployed - irrespective of ability - as well as between vacancies. Due to CRS, the flow probability of a worker to match a vacancy $\mu_{i}$ and the flow probability of a vacancy to match a worker $\eta_{i}$ only depend on the ratio of vacancies to job-seekers, the so-called market tightness $\theta_{i} \equiv v_{i} / u_{i}$. Hence, $\mu_{i} \equiv m_{0} M_{i} / u_{i}=\mu\left(\theta_{i}\right)$, and $\eta_{i} \equiv m_{0} M_{i} / v_{i}=\mu\left(\theta_{i}\right) / \theta_{i}$.

Assumption 2 The function $\mu$ is strictly increasing, satisfies the boundary conditions $\mu(0)=0$ and $\lim _{\theta \rightarrow \infty} \mu(\theta)=\infty$, and the Inada conditions $\lim _{\theta \rightarrow 0} \mu^{\prime}(\theta)=\infty$, and $\lim _{\theta \rightarrow 0} \mu(\theta)=\infty$

These standard properties imply the function $\eta$ is strictly decreasing from infinity to 0.

Flows and stocks. Let $\Omega_{i t}, i=h, l, e$ denotes the sub-set of $\mathbb{R}_{+} \times \mathbb{R}_{+}$that induces, respectively, the choice of schooling (and, therefore, of participating to the high-skill sector), participating to the low-skill sector, and non-participating at time $t$. Since schooling is costly, non-participating workers do not get an education and the intersection of the various subsets taken by pairs is empty, that is $\Omega_{i t} \cap \Omega_{j t}=\emptyset$ for $i \neq j$. In addition, $\cup_{i} \Omega_{i t}=\Omega$.

The size of the labour force $n_{i}$ on sector $i=h, l$ evolves according to

$$
d n_{i} / d t=\delta \iint_{\Omega_{i t}} \phi(a, c) d c d a-\delta n_{i}
$$


The only source of separation is the workers' death (retirement). The rate of unemployment $u_{i}$ and the mass-numbers of employees $l_{i}$ in sector $i$ obey the following law of motion:

$$
\begin{aligned}
d u_{i} / d t & =\frac{\delta \iint_{\Omega_{i t}} \phi(a, c) d c d a}{n_{i}}-\left(\mu_{i}+\delta\right) u_{i} \\
l_{i} & =n_{i}\left(1-u_{i}\right)
\end{aligned}
$$

Entrants make up the inflow into unemployment in each sector, while the outflow is equal to the sum of hires and the number of deaths. In steady-state, $\Omega_{i t}=\Omega_{i}$ for all $t$ and $d n_{i} / d t=d u_{i} / d t=0$. It follows that

$$
\begin{aligned}
n_{i} & =\iint_{\Omega_{i}} \phi(a, c) d c d a \\
u_{i} & =\frac{\delta}{\mu_{i}+\delta} \\
l_{i} & =\frac{\mu_{i}}{\mu_{i}+\delta} n_{i}
\end{aligned}
$$

Aggregate output in sector $i$ is worth

$$
Y_{i}=A_{i} l_{i} \bar{a}_{i}
$$

where

$$
\bar{a}_{i} \equiv \mathbb{E}\left[a \mid(a, c) \in \Omega_{i}\right]
$$

is the average ability among workers in sector $i$.

Aggregate schooling cost is

$$
C \equiv \delta \iint_{\Omega_{h}} \phi(a, c) c d c d a
$$

\subsection{Decentralized economy}

Agents' gains. In the decentralized economy, the allocation of workers between sectors is driven by self-selection in education, while sectorial job creation depends on firms' incentives to enter the search market. In sum, the assignment of workers to sectors depends on private gains expected by firms and workers. We assume as it is common in the literature that the size of rents accruing to each party when a match occurs is determined by ex-post Nash bargaining.

Let $U_{i a}$ and $W_{i a}$ be the respective values of being unemployed and employed in sector $i$ for a type $a$ worker. Let also $V_{i}$ and $J_{i a}$ denote the values of a sector $i$-vacant job and of a sector $i$-filled job with a similar worker. 
Denoting the wage rate by $w_{i a}$, these values satisfy the arbitrage equations:

$$
\begin{aligned}
r U_{i a} & =\mu_{i}\left[W_{i a}-U_{i a}\right] \\
r W_{i a} & =w_{i a} \\
r J_{i a} & =y_{i a}-w_{i a}+\delta V_{i} \\
\rho V_{i} & =-\gamma+\eta_{i}\left[\mathbb{E}\left(J_{i a} \mid(a, c) \in \Omega_{i}\right)-V_{i}\right]
\end{aligned}
$$

As it is standard, each value can be considered an asset value. The return to the asset is equal to the flow benefit (or loss), plus the expected gain (loss) resulting from a potential change of state. Equation (2.15) deserves additional comments. Random matching in each sector implies the type $a$ of the incoming worker is a priori unknown to the employer. This justifies the conditional mean operator $\mathbb{E}$.

Wages are determined by Nash bargaining:

$$
\beta\left[J_{i a}-V_{i}\right]=(1-\beta)\left[W_{i a}-U_{i a}\right]
$$

where $\beta \in(0,1)$ is the worker's exogenous bargaining power.

Schooling, non-participation and tightness. We present how (i) non-participation, (ii) self-selection in education and (iii) sector-specific market tightness are determined.

(i) Non-participants get a negative return from their participation to each sector. Formally, an agent endowed with ability $a$ and schooling cost $c$ does not participate to the labour market if and only if

$$
\max \left\langle U_{l a}, U_{h a}-c\right\rangle<0
$$

(ii) Each agent compares her utility if she decided to get an education (net of the schooling cost) to that she would get if she decided to remain uneducated. Therefore, an agent endowed with ability $a$ and schooling cost $c$ becomes educated if and only if

$$
U_{h a}-c \geq \max \left\langle U_{l a}, 0\right\rangle
$$

(iii) Firms enter the search market until the exhaustion of all rents. Free entry implies

$$
V_{i}^{v} \leq 0
$$

In the rest of the paper, we focus on the case where $\rho$ tends to 0 . This assumption is usual in the search literature and does not seem particularly restrictive. It provides a simple rationale for the reason why we only focus on steady states. 


\subsection{Centralized economy}

In the centralized economy, a social planner chooses the number of vacancies in each sector as well as the assignment of workers to sectors - the allocation of talents. The planner takes the joint distribution of schooling cost and ability as given ${ }^{8}$ and maximizes the discounted path of aggregate consumption. When the rate of time preference $\rho$ tends to 0 , we have:

$$
\mathbf{S}=\max _{\Omega_{i}, v_{i}}\left\langle\sum_{i}\left(Y_{i}-\gamma v_{i}\right)-C\right\rangle
$$

This is the sum of sector-specific output net of search costs, minus aggregate schooling costs. Using the definitions above, and taking account of the fact that $v_{i}=\theta_{i} u_{i}$, we get

$$
\mathbf{S}=\max _{\Omega_{i}, \theta_{i}}\left\langle\sum_{i=h, l} \iint_{\Omega_{i}} \phi(a, c)\left(1-u_{i}\right)\left[A_{i} a-\delta \frac{\gamma}{\eta\left(\theta_{i}\right)}\right] d c d a-\delta \iint_{\Omega_{h}} \phi(a, c) c d c d a\right\rangle
$$

subject to $u_{i}=\delta /\left(\delta+\mu\left(\theta_{i}\right)\right), \Omega_{i} \subset \mathbb{R}_{+} \times \mathbb{R}_{+}, \Omega_{i} \cap \Omega_{j}=\emptyset$ for all $i \neq j$, and $\cup_{i} \Omega_{i}=\mathbb{R}_{+} \times \mathbb{R}_{+}$.

As a first step, we turn to the frictionless environment.

\section{Walrasian allocation}

In this section, we analyse the properties of the walrasian economy. A walrasian environment is taken here to be an environment where frictions are negligible. It is thus assumed that the scale parameter of the matching technology $m_{0}$ tends to infinity. We show the assignment of workers to jobs through self-selection in education is socially efficient.

\subsection{Decentralized economy}

When $m_{0}$ tends to infinity, the value of search tends to the value of employment. From the Nash bargaining equation (2.16), the value of a filled job for the firm tends to 0 . Consequently, the wage is equal to the output flow:

$$
w_{i a}=y_{i a}
$$

As $y_{i a} \geq 0$, all agents participate to the labour market and $\Omega_{e}^{*}=\emptyset$. Self-selection in education is given by (2.18), which can be written as

$$
(a, c) \in \Omega_{h}^{*} \text { iff } A_{h} a / \delta \geq A_{l} a / \delta+c
$$

\footnotetext{
${ }^{8}$ The planner could actually alter the schooling costs. For instance, if heterogenous schooling costs resulted from credit constraints, the planner could reduce aggregate schooling costs simply by reallocating financial resources among agents. This standard market failure is not taken into account here.
} 
From this equation, we can draw an indifference locus in the $(a, c)$ plane, that is the set of characteristics of agents indifferent between acquiring higher education or remaining lowly educated:

$$
c=R^{*} a
$$

where $R^{*} \equiv\left(A_{h}-A_{l}\right) / \delta$ is the return to schooling, that is the differential return to ability in the high and low productivity sectors. It is increasing in the productivity differential $A_{h}-A_{l}$, and it is independent of the workers' ability. Figure 3.1 depicts the assignment of agents to sectors. Individuals whose characteristics are below the indifference locus get an education. Conversely, those whose characteristics are above the locus remain uneducated.

There are uneducated workers as far as there exist individuals with low ability and high schooling costs. There are also educated workers since some high ability individuals are endowed with low schooling costs. Agents may decide not to invest in education either because the cost of their schooling is too high (despite potentially large ability levels), or because their ability is too poor (despite low schooling costs). Note that in the absence of any restrictions on the joint distribution of schooling costs and ability, the mean ability among the educated may well be higher or lower than the mean ability among the uneducated. But this has no consequences on individual choices: in the frictionless economy, a worker's return to schooling does not depend on the composition of education groups. Crucially, this property does not hold in the frictional environment.

This mechanism of self-selection refers to Roy (1951), where a continuum of (heterogenous) workers select themselves between a discrete number of occupations. Each individual is characterized by a bundle of sector-specific skills, and chooses which sector to enter on the basis of comparative advantage. In our model, there is a unique labour market ability common to each sector ${ }^{9}$. This implies the returns to ability in the lowand high-skill sectors are perfectly correlated. However, there is a cost of entry to the high-skill sector which is assumed to differ across the population. If one considers utilities obtained in each case instead of abilities, that is $U_{h}=A_{h} a / \delta-c$ and $U_{l}=A_{l} a / \delta$, then Roy's setup and ours are equivalent in terms of the payoffs the agents can expect.

\subsection{Centralized economy}

The social criterion is worth

$$
\mathbf{S}=\max _{\Omega_{i}}\left\langle\sum_{i=h, l} \iint_{\Omega_{i}} \phi(a, c) A_{i} a d c d a-\delta \iint_{\Omega_{h}} \phi(a, c) c d c d a\right\rangle
$$

\footnotetext{
${ }^{9}$ Moscarini (2001) builds on and extends Roy's setup to an environment with frictions, but does not consider the normative implications of his model. The decentralized economy of our model and Moscarini's converge towards (formally) similar walrasian allocations as search frictions die down.
} 


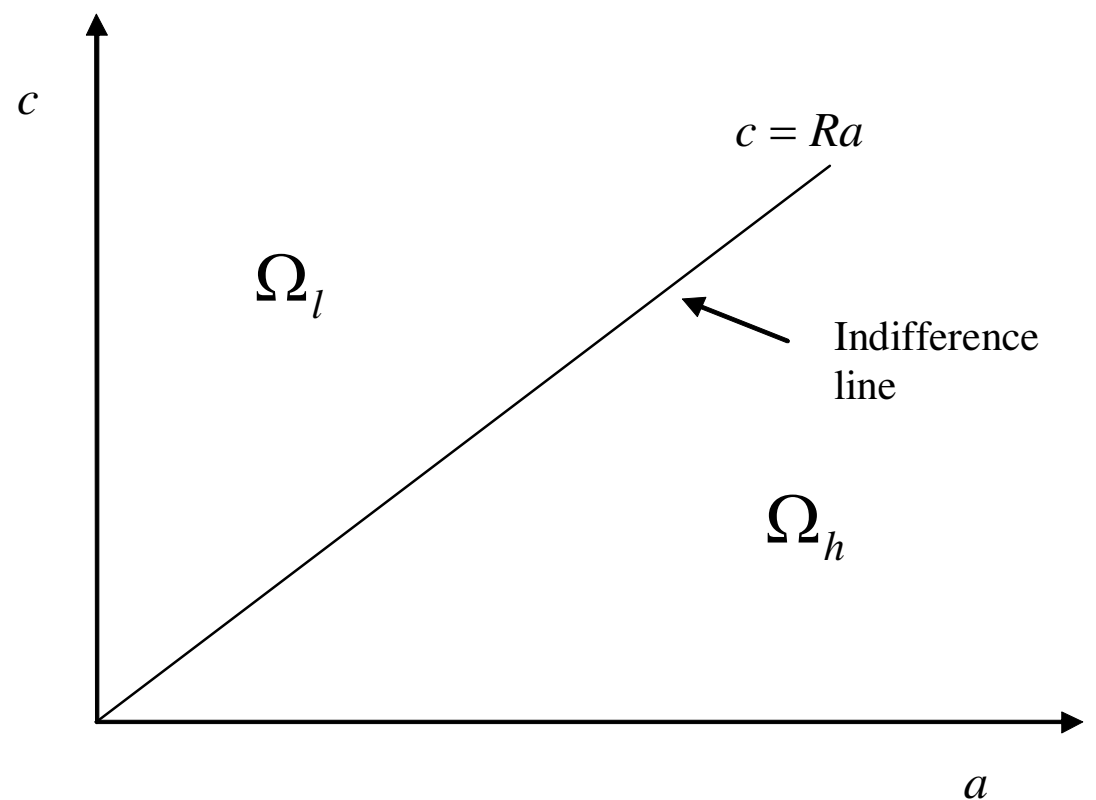

Figure 3.1: The allocation of talents in the walrasian economy. Agents whose characteritics are below the line get educated, while the others remain uneducated.

In the absence of externality, the fact that $y_{i a} \geq 0$ implies (like the decentralized economy) $\Omega_{e}^{s}=\emptyset$. A type $a$ worker gets an education if and only if her net contribution to the social criterion is non-negative, that is

$$
(a, c) \in \Omega_{h}^{s} \text { iff } A_{h} a \geq A_{l} a+\delta c
$$

It follows that the social return to schooling $R^{s}=R^{*}$ and $\Omega_{h}^{*}=\Omega_{h}^{s}$. Consequently, self-selection is socially efficient.

The introduction of matching frictions dramatically alters this result, as we demonstrate below.

\section{Frictional environment}

In this section, we show search frictions originate two important externalities implying the private return differs from the social return to schooling. On the one hand, self-selection in education originates a composition externality that relates sector-specific wages and employment opportunities to sector-specific mean ability. Due to this externality, poorly able but rich individuals crowd out abler but poorer individuals from schooling. On the other hand, ex-post Nash bargaining generally fails to internalize standard congestion externalities. It follows the returns to each type of occupation are below the social returns. As a consequence, there may be over-education at all schooling costs. 


\subsection{Decentralized economy}

A worker endowed with innate characteristic $a$ working in sector $i$ is paid a wage $w_{i a}$ such that

$$
w_{i a}=\beta \frac{\delta+\mu_{i}}{\delta+\beta \mu_{i}} y_{i a}
$$

The wage equation (4.1) features standard properties: a worker gets a share $\beta\left(\delta+\mu_{i}\right) /\left(\delta+\beta \mu_{i}\right)$ of the output flow $y_{i a}$ through the Nash bargain. This share increases with tightness and bargaining power; it decreases with interest rate (see Pissarides, 2000). The wage is also increasing with the output flow $y_{i a}$ which raises the size of the surplus to be shared between firms and workers. The value of search is then

$$
U_{i a}=\frac{\beta \mu_{i}}{\delta+\beta \mu_{i}} \frac{y_{i a}}{\delta}
$$

Like in the walrasian case, $y_{i a} \geq 0$ implies $U_{i a} \geq 0$, and therefore all agents are willing to participate to the labour market in the decentralized outcome. Hence $\Omega_{e}=\emptyset$. According to the self-selection rule (2.18), self-selection in education is now given by

$$
(a, c) \in \Omega_{h} \text { iff } \frac{\beta \mu_{h}}{\delta+\beta \mu_{h}} \frac{A_{h} a}{\delta} \geq \frac{\beta \mu_{l}}{\delta+\beta \mu_{l}} \frac{A_{l} a}{\delta}+c
$$

The main difference with the walrasian case is that the discounted value of output in each sector is weighted by a term lower than one which reflects employment opportunities and bargaining power in each sector - this term tends to one as $\mu_{i}$ tends to infinity.

As in the walrasian case, we can define the set of individuals indifferent between being educated or remaining uneducated:

$$
c=\left[\frac{\beta \mu_{h}}{\delta+\beta \mu_{h}} \frac{A_{h}}{\delta}-\frac{\beta \mu_{l}}{\delta+\beta \mu_{l}} \frac{A_{l}}{\delta}\right] a
$$

Like the walrasian case, equation (4.4) defines a linear relationship between schooling cost and ability. The slope of the curve is again the private return to schooling:

$$
R \equiv \frac{\beta \mu_{h}}{\delta+\beta \mu_{h}} \frac{A_{h}}{\delta}-\frac{\beta \mu_{l}}{\delta+\beta \mu_{l}} \frac{A_{l}}{\delta}
$$

It depends positively on the high-skill sector tightness, and negatively on the low-skill sector tightness. Moreover, like the walrasian case, the private return to schooling does not depend on ability.

Market tightness in each sector is determined by

$$
\frac{\gamma}{\eta\left(\theta_{i}\right)}=\frac{(1-\beta) A_{i} \bar{a}_{i}}{\delta+\beta \mu\left(\theta_{i}\right)}
$$

The left-hand side is the mean search cost incurred by firms; the right-hand side is the expected value of a filled job. As $\eta_{i}$ is strictly decreasing in tightness, equation (4.6) 
implies tightness is an increasing function of average ability in each sector. The Beveridge curve then implies that the unemployment rate in each sector is a decreasing function of sector-specific average ability $\bar{a}_{i}$. Here is the key point of the paper: while comparing the returns to being educated or uneducated, the agents do not take into account the effect of their choice on average ability in each sector. However, the average ability in each sector determines wage and employment opportunities.

\section{Proposition 1 A characterization of the Decentralized allocation}

There exists a vector $\left(\theta_{l}^{*}, \theta_{h}^{*}, \bar{a}_{l}^{*}, \bar{a}_{h}^{*}, R^{*}\right)$ satisfying the following conditions

(i) free entry

$$
\frac{\gamma}{\eta\left(\theta_{i}^{*}\right)}=\frac{(1-\beta) A_{i} \bar{a}_{i}^{*}}{\delta+\beta \mu\left(\theta_{i}^{*}\right)}, i=h, l
$$

(ii) self-selection

$$
\bar{a}_{l}^{*}=\mathbb{E}\left[a \mid c>R^{*} a\right] \text { and } \bar{a}_{h}^{*}=\mathbb{E}\left[a \mid c \leq R^{*} a\right]
$$

(iii) return to schooling

$$
R^{*}=\frac{\beta \mu\left(\theta_{h}^{*}\right)}{\delta+\beta \mu\left(\theta_{h}^{*}\right)} \frac{A_{h}}{\delta}-\frac{\beta \mu\left(\theta_{l}^{*}\right)}{\delta+\beta \mu\left(\theta_{l}^{*}\right)} \frac{A_{l}}{\delta}
$$

where, by convention, $\mathbb{E}[a \mid c<0]=0$.

Two different configurations may arise. In the first, there is an interior equilibrium: the return to schooling $R^{*}>0$ and the two sectors coexist. In the second, none gets an education and the educated sector is closed.

Assumption $3 \mathbb{E}(a \mid c \leq b a-d)>\mathbb{E}(a \mid a \geq d / b)$ for all $b>0, d \geq 0$

\section{Proposition 2 EXISTENCE OF AN INTERIOR EQUILIBRIUM}

There exists an interior equilibrium with $\bar{a}_{l}^{*}<\mathbb{E}(a)<\bar{a}_{h}^{*}$

The result is established by mean of a fixed-point argument. According to (4.6), tightness is an increasing function of sector-specific ability, i.e. $\theta_{i} \equiv \Theta_{i}\left(\bar{a}_{i}\right)$. In turn, the return to schooling $R$ is an increasing function of $\theta_{h}$, and a decreasing function of $\theta_{l}$. Together, these properties imply $R \equiv \Re\left(\Theta_{h}\left(\bar{a}_{h}\right), \Theta_{l}\left(\bar{a}_{l}\right)\right)$. Solving then reduces to determine the fixed-point of

$$
\begin{aligned}
& \bar{a}_{l}^{*}=\mathbb{E}\left[a \mid c>\Re\left(\Theta_{h}\left(\bar{a}_{h}^{*}\right), \Theta_{l}\left(\bar{a}_{l}^{*}\right)\right) a\right] \\
& \bar{a}_{h}^{*}=\mathbb{E}\left[a \mid c \leq \Re\left(\Theta_{h}\left(\bar{a}_{h}^{*}\right), \Theta_{l}\left(\bar{a}_{l}^{*}\right)\right) a\right]
\end{aligned}
$$


Like the walrasian case, the existence of low ability individuals with high schooling costs guarantees some agents remain uneducated, that is $\Omega_{l}^{*} \neq \emptyset$. But unlike the walrasian case, the fact that there are high ability individuals with low schooling costs does not ensure some agents get an education. Indeed, as we mentioned above, self-selection does not necessarily lead to a higher mean ability in the high-skill sector, especially when schooling cost and ability are strongly positively correlated. In a frictional environment, $\bar{a}_{h}<\bar{a}_{l}$ may imply the return to schooling is negative. In this case, no one gets an education and there is no high-skill sector. This results from an adverse selection phenomenon which takes place at the market level : high ability workers would be willing to get an education, but if those workers decided to educate, this would also make the high-skill sector attractive for low ability workers. This would deteriorate sector-specific tightness by too much, implying the high ability workers would remain uneducated.

However, Assumption 3 avoids such a situation: as far as the return to schooling is positive, the mean ability in the high-skill sector is higher than the unconditional mean ability ${ }^{10}$. This also implies the mean ability in the low-skill sector is below the unconditional mean ability. These properties in turn imply the return to schooling is positive, which sustains the existence of at least one interior equilibrium.

Assumption 3 also reduces the scope for multiple equilibria. Consider for instance the following multiplier effect: as average ability in the high-skill sector increases, so does firms' incentives to create jobs in this sector, and as more jobs are created, it increases the incentives for more people to get educated. If these marginal people are of the high-ability, high-cost type, this may cause a further rise in the average ability in the high-skill sector, thus perpetuating the process. Under Assumption 3, the increase in the proportion of educated workers involves a decrease in the average ability of educated individuals.

\subsection{Centralized economy}

To describe the efficient allocation, it is convenient to define the social return to ability in sector $i, P_{i}^{s}$, and the social return to schooling $R^{s}$ as follows:

$$
\begin{aligned}
P_{i}^{s}(a) & =\left(1-u_{i}\right)\left[\frac{A_{i} a}{\delta}-\frac{\gamma}{\eta_{i}}\right] \frac{1}{a} \\
R^{s}(a) & =P_{h}^{s}(a)-P_{l}^{s}(a)
\end{aligned}
$$

Sector-specific return to ability can be written as the employment rate $1-u_{i}$, times the value of output net of the per employee recruitment cost, divided by ability. Importantly, the contribution of each to output is increasing in ability, while corresponding recruitment costs do not vary with ability. The social return to schooling is the differential return to ability in each sector.

\footnotetext{
${ }^{10}$ Proposition 2 only requires that Assumption 3 holds for $d=0$.
} 
The following characterization of the efficient allocation is derived from the first-order conditions to the maximization program (3.4) - see the proof of Proposition 3. The set of non-participating agents is given by

$$
(a, c) \in \Omega_{e}^{s} \text { iff } P_{l}^{s}(a)<0 \text { and } P_{h}^{s}(a) a<c
$$

Non-participants are those whose social return to participation is negative in the lowskill sector, and lower than the schooling cost in the high-skill sector. For short, nonparticipants have low ability that does yield sufficient output compared to the expected search spending. Unlike the decentralized allocation, the efficient allocation is characterized by a set of non-participating agents, that is $\Omega_{e}^{s} \neq \emptyset$.

The set of highly-educated agents is defined by

$$
(a, c) \in \Omega_{h}^{s} \text { iff } P_{h}^{s}(a) \geq 0 \text { and } R^{s}(a) a \geq c
$$

Educated individuals are those whose return to ability in the high-skill sector is nonnegative, and the return to schooling times their ability is larger than the schooling cost. Note the latter condition does not imply the former, as the return to participation in the low-skill sector may be negative.

Finally, the amount of resources dedicated to search is given by

$$
\frac{\gamma}{\eta\left(\theta_{i}^{s}\right)}=\alpha_{i}^{s} \frac{A_{i}}{\delta+\left(1-\alpha_{i}^{s}\right) \mu\left(\theta_{i}^{s}\right)} \bar{a}_{i}^{s}, i=h, l
$$

where $\alpha_{i}^{s} \equiv \theta_{i}^{s} \mu^{\prime}\left(\theta_{i}^{s}\right) / \mu\left(\theta_{i}^{s}\right)$ and $\bar{a}_{i}^{s} \equiv \mathbb{E}\left[a \mid(a, c) \in \Omega_{i}^{s}\right]$. Like the decentralized economy, sector-specific tightness is increasing in sector-specific mean ability. In addition, we have $\theta_{h}^{s}>\theta_{l}^{s}$ as long as $\bar{a}_{h}^{s} \geq \bar{a}_{l}^{s}$. However, this condition does not always hold.

\section{Proposition 3 A characterization of the efficient allocation}

There exists a vector $\left(\theta_{l}^{s}, \theta_{h}^{s}, \bar{a}_{l}^{s}, \bar{a}_{h}^{s}\right)$ and three functions $P_{h}^{s}, P_{l}^{s}, R^{s}$ mapping $\mathbb{R}_{+}$into $\mathbb{R}$ such that

(i) tightness

$$
\frac{\gamma}{\eta\left(\theta_{i}^{s}\right)}=\alpha_{i}^{s} \frac{A_{i}}{\delta+\left(1-\alpha_{i}^{s}\right) \mu\left(\theta_{i}^{s}\right)} \bar{a}_{i}, i=h, l
$$

(ii) allocation of talents

$$
\bar{a}_{l}^{s}=\mathbb{E}\left[a \mid c>R^{s}(a) a, P_{l}^{s}(a) \geq 0\right] \text { and } \bar{a}_{h}^{s}=\mathbb{E}\left[a \mid c \leq R^{s}(a) a, P_{h}^{s}(a) \geq 0\right]
$$

(iii) return to schooling

$$
R^{s}(a)=P_{h}^{s}(a)-P_{l}^{s}(a)
$$


(iv) return to participation in each sector

$$
P_{i}^{s}(a)=\frac{\left(1-\alpha_{i}^{s}\right) \mu\left(\theta_{i}^{s}\right)}{\delta+\left(1-\alpha_{i}^{s}\right) \mu\left(\theta_{i}^{s}\right)} \frac{A_{i}}{\delta}+u_{i}^{s} \frac{\alpha_{i}^{s} \mu\left(\theta_{i}^{s}\right)}{\delta+\left(1-\alpha_{i}^{s}\right) \mu\left(\theta_{i}^{s}\right)} \frac{A_{i}}{\delta} \frac{a-\bar{a}_{i}}{a}
$$

with $\alpha_{i}^{s} \equiv \theta_{i}^{s} \mu^{\prime}\left(\theta_{i}^{s}\right) / \mu\left(\theta_{i}^{s}\right), u_{i}^{s}=\delta /\left(\delta+\mu\left(\theta_{i}^{s}\right)\right)$.

Proposition 3 synthesizes the allocation chosen by the central planner and, doing so, states two important properties. First, the return to ability in each sector depends on individual ability. It can be written as follows:

$$
P_{i}^{s}(a)=P_{i}^{s}\left(\bar{a}_{i}^{s}\right)+u_{i}^{s} \frac{\alpha_{i}^{s}}{1-\alpha_{i}^{s}} P_{i}^{s}\left(\bar{a}_{i}^{s}\right) \frac{a-\bar{a}_{i}}{a}
$$

The first term is sector-specific and denotes the individual contribution to aggregate welfare at given sector-specific tightness. The second term is individual-specific and takes into account the impact of the agent on sector-specific tightness through congestion effects. It depends on ability: it is negative (positive) for individuals whose ability is below (above) the mean. Of course, it is nil when the workforce is homogenous. As the return to schooling $R^{s}(a)$ equals the differential return to ability, it is unclear whether it is increasing in ability or not. The answer actually depends on the joint distribution of schooling cost and ability.

Second, $\bar{a}_{i}^{s}>0$ for $i=h, l$ implies that, unlike the decentralized economy, there are always uneducated and educated workers, i.e. $\Omega_{i}^{s} \neq \emptyset$ for $i=h, l$. Even when the social return to schooling is decreasing in ability, low ability agents are assigned to the high-skill sector, while abler individuals are assigned to the low-skill sector. Why is this so? In the decentralized economy, the return to schooling is the same for all individuals. When it is positive, all agents are willing to get an education, but schooling costs prevent some of them to do so. Conversely when it is negative, all agents remain uneducated. Despite they are more productive in the high-skill sector, low ability agents realize they would benefit from better job and wage opportunities in the low-skill sector. Indeed, the mean ability is much higher in the latter sector, which in turn implies the corresponding search market is tighter too. In the centralized economy, the social planner takes account of the fact low ability individuals would deteriorate by too much the average ability among the uneducated if assigned to this sector. Therefore, these workers are allocated to the high-skill sector.

Proposition $4 \bar{a}_{l}^{s}<\bar{a}_{h}^{s}$ if and only if

(i) $R^{s}(a)$ and $R^{s}(a)$ a are strictly increasing in a

(ii) $P_{l}^{s}(a) \geq 0$ when $R^{s}(a) \geq 0$ 


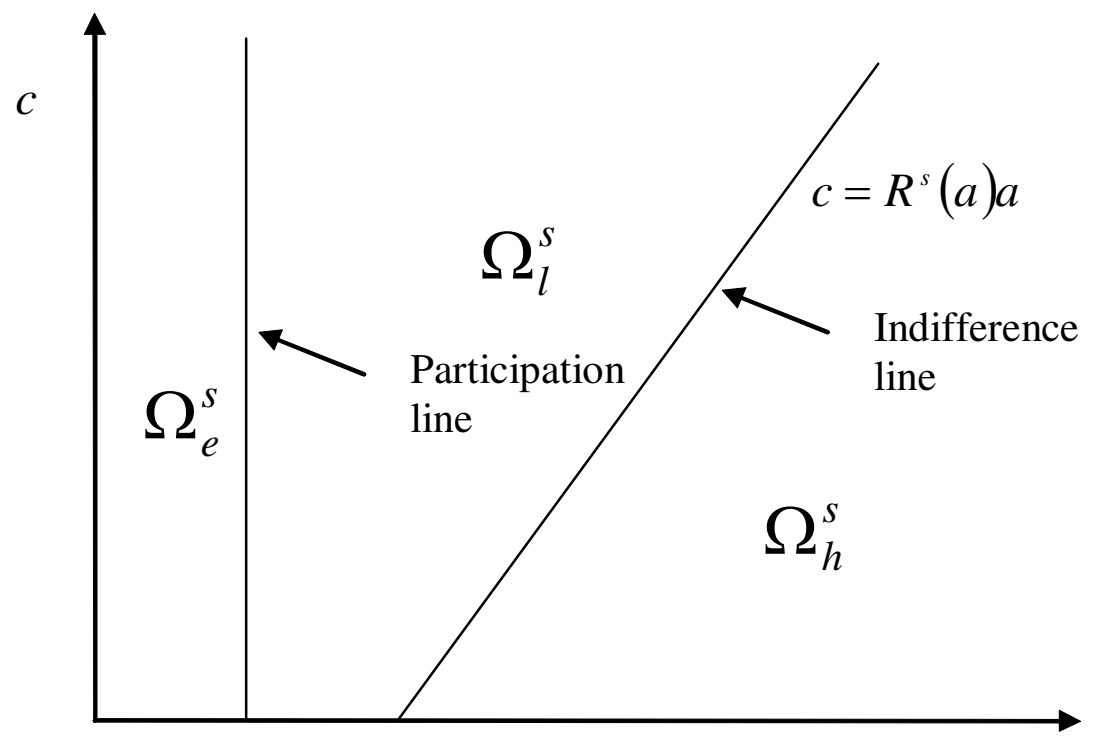

$a$

Figure 4.1: The efficient allocation of talents with search frictions. Agents whose characteristics are located on the left of the participation line do not participate. Agents whose characteristics are below the indifference line get educated. The others remain uneducated.

Proposition 4 provides two pieces of information. First, when the mean ability among the educated is larger than among the uneducated, the efficient allocation can be depicted by Figure 4.1 .

There are two lines. The set of non-participating agents $\Omega_{e}^{s}$ is on the left of the participation line; the set of educated individuals $\Omega_{h}^{s}$ is below the (positively sloped) indifference line; the set of uneducated participating agents $\Omega_{l}^{s}$ is located between the two lines. The high-skill search market is tighter than the low-skill one, i.e. $\theta_{l}^{s}<\theta_{h}^{s}$, the return to ability is larger in the high-skill sector, i.e. $P_{h}^{s}(a) \geq P_{l}^{s}(a)$, and, finally, the return to schooling is positively related to ability. In addition, if the return to schooling is non-negative, then the return to ability in the low-skill sector is also non-negative.

Second, if the efficient allocation is given by Figure 4.1, then $\bar{a}_{l}^{s}<\bar{a}_{h}^{s}$. This property is actually induced by Assumption 3, which plays here a similar role to the one played in the decentralized economy ${ }^{11}$.

Importantly, Proposition 4 does not say which allocation is chosen by the planner. The efficient allocation may well be such that $\bar{a}_{l}^{s}>\bar{a}_{h}^{s}$. The following result prevents such a case to occur.

\footnotetext{
${ }^{11}$ Note, however, that Proposition 2 only requires that Assumption 3 holds for $d=0$, while Proposition 4 requires that Assumption 3 holds for all $d$.
} 


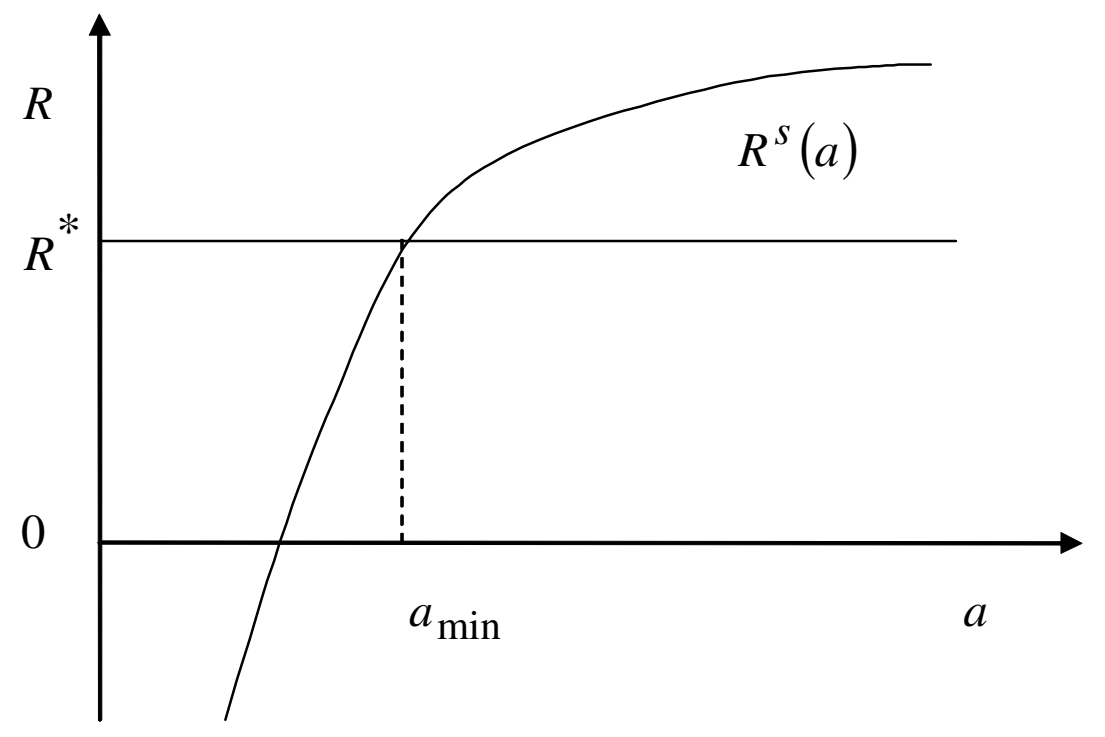

Figure 4.2: Efficient vs decentralized return to schooling in case (i) of Proposition 6. Agents whose ability is lower than $a_{\text {min }}$ overestimate the return to schooling, while the others underestimate it.

Proposition $5 \bar{a}_{l}^{s}<\bar{a}_{h}^{s}$ if $A_{h}$ is sufficiently large

Hereafter, we shall assume the efficient allocation is the one described by Proposition 4 .

How much does the decentralized allocation differ from the efficient allocation? This issue is investigated in the next sub-section.

\subsection{The inefficiency of the decentralized outcome}

We start the discussion by comparing private and social returns to schooling.

Proposition 6 Efficient vs Equilibrium returns to Schooling

If $\bar{a}_{l}^{s}<\bar{a}_{h}^{s}$, one of the two following cases prevails:

(i) There exists a unique $a_{\lim }>0$ such that $R^{s}(a) \lesseqgtr R^{*}$ iff $a \lesseqgtr a_{\lim }$, or

(ii) $R^{s}(a)<R^{*}$ for all $a \geq 0$

Figure 4.2 depicts the social return to schooling in case (i).

Unlike the social return to schooling, the private return does not depend on individual ability. Thus, agents do not select themselves enough on the basis of ability: those endowed with a low ability over-estimate the return to their schooling, while on the contrary, abler individuals may underestimate their's. 
However, high ability individuals may also face too high private returns to schooling. This property is due to Nash bargaining, and not to skill heterogeneity. To see this, suppose the distribution of ability is degenerate and consider the private and social returns to schooling:

$$
R^{*}=U_{h}(\beta)-U_{l}(\beta) \text { and } R^{s}=U_{h}\left(1-\alpha_{h}\right)-U_{l}\left(1-\alpha_{l}\right)
$$

where the equilibrium dependence vis-à-vis $\beta$ has been highlighted. When the Hosios condition holds, job creation is efficient in each sector; so is the private return to search in each sector and, as a consequence, the private return to schooling equals the social return. However, when the Hosios condition is not satisfied, the return to search in the two sectors are generally too low, as $U_{i}(\beta)<U_{i}\left(1-\alpha_{i}\right)$. As a consequence, the private return to schooling is generally different from the social return. Overeducation may then take place whenever $U_{h}(\beta)-U_{h}\left(1-\alpha_{h}\right)>U_{l}(\beta)-U_{l}\left(1-\alpha_{l}\right)$. For instance, this is the case $^{12}$ when $\beta=1-\alpha_{h} \neq 1-\alpha_{l}$.

We now analyse the consequences of proposition 6 on the efficiency of the decentralized allocation of talents across sectors.

\section{Proposition 7 A Characterization of over- AND Under-EDUCATION}

Let $x^{j}, j=*, s$, be two functions defined on $[0, \infty)$ such that

$$
x^{j}(c)=\int_{c \leq R^{j}(a) a} \phi(a, c) d a
$$

If $\bar{a}_{l}^{s}<\bar{a}_{h}^{s}$, one of the two following cases prevails:

(i) There exists a unique $c_{\lim } \equiv R^{*} a_{\lim }$ such that $x^{*}(c) \gtreqless x^{s}(c)$ iff $c \lesseqgtr c_{\lim }$

(ii) $x^{*}(c)>x^{s}(c)$ for all $c \geq 0$

We compare the number of educated individuals whose schooling cost is $c$ in the decentralized economy $x^{*}(c)$ to the number $x^{s}(c)$ chosen by the social planner. The difference between these two numbers offers a measure of under- or over-education at schooling cost $c$. Proposition 7 shows that high schooling cost individuals always overeducate, while under-education may occur at lower schooling costs.

\footnotetext{
${ }^{12}$ This suggests another potential channel through which Nash bargaining may translate into overeducation: sector-specific bargaining powers, of which the uneducated would typically be higher than $1-\alpha_{l}$. We did not consider this possibility for two reasons. First, wages are bargained individually in the model, and not collectively. In that way, the bargaining power is more likely individual-specific rather than sector-specific. Second, this would raise additional difficulties while stating the existence of a decentralized equilibrium.
} 


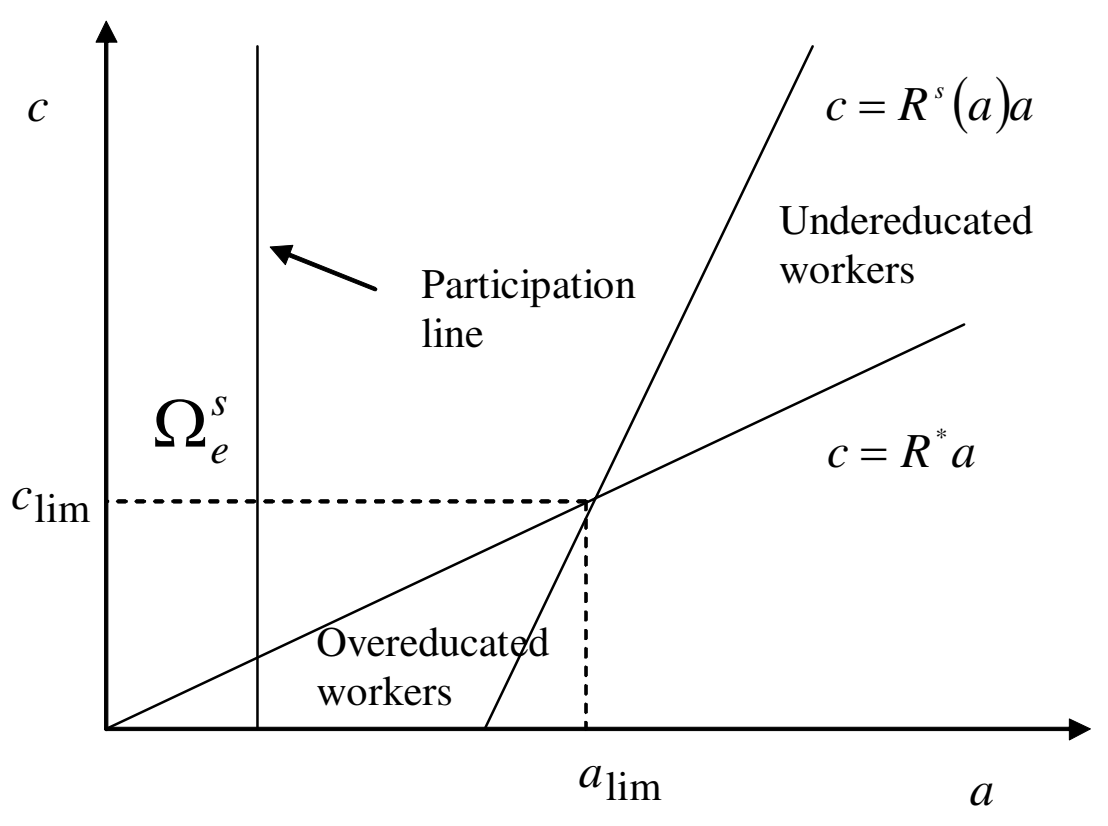

Figure 4.3: Overeducation for the rich, undereducation for the poor. There are overeducated agents at low schooling costs, while there are undereducated agents at high schooling costs.

The situation is depicted by Figures 4.3 and 4.4, which confront the decentralized allocation of talents to the efficient one. These figures display the two following properties. First, workers endowed with a very low ability are excluded from the labour market in the efficient allocation, while they are not in the decentralized case. Second, over-education prevails among the low schooling cost workers - the rich. This is a consequence of the minimum skill requirement in the efficient allocation.

In Figure 4.3, the slope of the social differential return to ability is higher than the slope of the private one. This implies under-education for high schooling cost individuals - the poor. Over-education among the rich and under-education among the poor explain why the slope of the differential return to ability is larger in the efficient economy. On the one hand, the poorly talented but rich individuals who get an education deteriorate the mean ability among the educated. This in turn reduces search prospects in the high-skill sector. On the other hand, highly talented but poor individuals who stay uneducated improve the mean ability among the uneducated. This raises wage and employment opportunities in the low-skill sector. Both effects lower the differential return to ability.

In Figure 4.4, the slope of the differential return to ability is higher in the efficient allocation than in the decentralized allocation. This implies over-education at all schooling costs. As suggested above, this situation occurs because workers' bargaining power generally fails to internalize search externalities. 


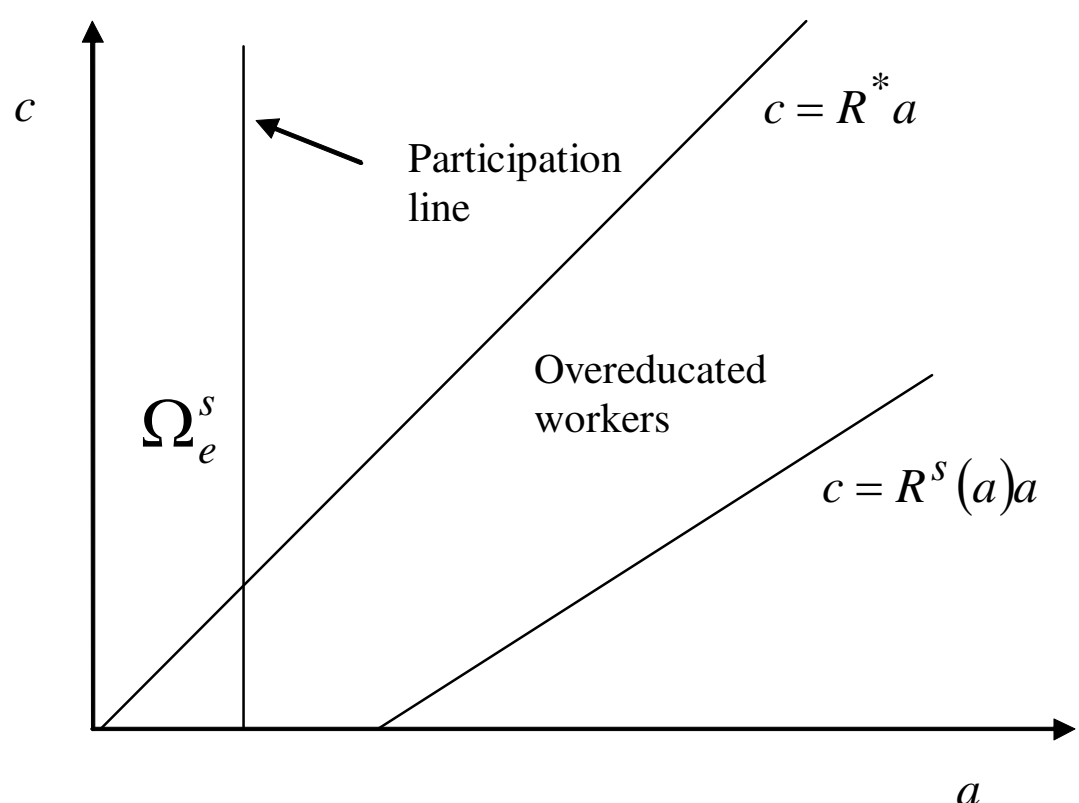

Figure 4.4: Overeducation for all. There are overeducated agents at all schooling costs.

\section{Education policy}

In this section, we study the optimal education policy - the policy maximizing aggregate welfare - in the case where ability is not observable, whereas schooling costs are. The education policy consists of two instruments: a lump-sum fee granted to all individuals willing to educate, and a subsidy proportional to their schooling costs. In addition, we focus on the case where the Hosios condition is met, and show that on average education should be taxed more than it should be subsidized.

Specific assumptions. We investigate the possibility to alter the decentralized outcome through taxes and subsidies, so as to replicate the efficient allocation. For this question to make sense, we consider the realistic environment in which the planner cannot observe individual ability, while the schooling cost is observable: in several papers (see among others Heckman, 2000, Cameron and Heckman, 2001, Carneiro and Heckman, 2001), it is argued that children's scholastic ability is strongly correlated to parental income. From this perspective, the individual schooling cost is observable as far as parents' income is observable.

To simplify, we also assume the social planner does not address the market failure originating from the participation of very low ability agents to the low-skill sector. This can be so either because the minimum of the support of the skill distribution is larger than the (socially) optimal minimum ability required to participate to the low-skill sector, or because there are huge costs associated to the exclusion of a fraction of the population 
from all economic activities - at least higher than the gain induced by the nonparticipation of the least able.

Decentralizing the first best allocation. The planner has two sets of policy instruments. First, $t_{i}, i=h, l$, is the sector-specific tax rate on output. Second, $\tau$ is the proportion of private schooling cost financed by the State, while $\bar{c}$ is a lump-sum tuition fee on education. Hence, the actual cost of schooling is worth $(1-\tau)(c+\bar{c}) \cdot{ }^{13}$

\section{Proposition 8 First Best in the DeCentralized ECONOMY}

Assume $\bar{a}_{h}^{s}>\bar{a}_{l}^{s}$ and let $\alpha_{i} \equiv \alpha\left(\theta_{i}^{s}\right), i=h, l$. The efficient allocation is decentralized iff

(i) $1-t_{i}=\frac{\alpha_{i}}{1-\beta} \frac{u_{i}+\beta\left(1-u_{i}\right)}{u_{i}+\left(1-\alpha_{i}\right)\left(1-u_{i}\right)}, i=h, l$

(ii) $\bar{c}=\frac{\alpha_{h}}{1-\alpha_{h}} u_{h} P_{h}^{s}\left(\bar{a}_{h}^{s}\right) \bar{a}_{h}^{s}-\frac{\alpha_{l}}{1-\alpha_{l}} u_{l} P_{l}^{s}\left(\bar{a}_{l}^{s}\right) \bar{a}_{l}^{s}>0$

(iii) $1-\tau=\frac{\beta}{1-\beta} \frac{\frac{\alpha_{h}}{1-\alpha_{h}} P_{h}^{s}\left(\bar{a}_{h}^{s}\right)-\frac{\alpha_{l}}{1-\alpha_{l}} P_{l}^{s}\left(\bar{a}_{l}^{s}\right)}{\left(1-u_{h}\right) A_{h} / \delta-\left(1-u_{l}\right) A_{l} / \delta}>0$

Sector-specific taxes on output allow to internalize search externalities, and compensate inadequate bargaining powers. Hence, the tax rate is positive if and only if $\beta<1-\alpha_{i}$, it is nil when $\beta=1-\alpha_{l}=1-\alpha_{h}$, and it is negative otherwise. The lump-sum tuition cost is equal to the social differential cost of participation to each sector; it deters the low ability agents with small schooling costs to invest in education. Finally, the proportion of schooling costs financed by the State $\tau$ is smaller than 1 .

When the Hosios condition is met. The study of the optimal schooling policy when the Hosios condition is met is particularly illuminating. We now assume $\beta=1-\alpha_{l}^{s}=$ $1-\alpha_{h}^{s}=1-\alpha$. To understand the optimal policy in this case, consider Figure 4.3. This figure depicts the efficient and decentralized allocations that would result if $\bar{a}_{i}^{s}=\bar{a}_{i}^{*}$. To make both allocations coincide, it is necessary to shift the decentralized indifference line by means of a clockwise rotation to the left. This can be reached by mean of a schooling fee, deterring the low ability and low schooling costs individuals to become educated, and a voucher increasing in schooling cost to attract abler workers with large schooling costs on the high-skill market ${ }^{14}$. Hence,

$$
\begin{aligned}
\bar{c} & =\frac{\alpha}{1-\alpha}\left[u_{h} P_{h}^{s}\left(\bar{a}_{h}^{s}\right) \bar{a}_{h}^{s}-u_{l} P_{l}^{s}\left(\bar{a}_{l}^{s}\right) \bar{a}_{l}^{s}\right] \\
1-\tau & =\frac{P_{h}^{s}\left(\bar{a}_{h}^{s}\right)-P_{l}^{s}\left(\bar{a}_{l}^{s}\right)}{\left(1-u_{h}\right) A_{h} / \delta-\left(1-u_{l}\right) A_{l} / \delta}
\end{aligned}
$$

\footnotetext{
${ }^{13}$ The proceed of all taxes is redistributed through equal and non-distorsive lump-sum transfers. If negative, we assume all agents are endowed with enough wealth to finance the lump-sum tax.

${ }^{14}$ Note that the optimal policy described here differs from what would result with credit market imperfections. In that latter case, income redistribution is a primary goal of education policy to decrease the aggregate schooling cost.
} 
The education policy is redistributive: low schooling cost individuals are taxed, while high-schooling costs individuals are subsidized.. This raises the following question: On average, should education be taxed more than it should be subsidized? Formally, each individual pays an additional $(1-\tau) \bar{c}$, but gets $\tau c$ back. Hence, $\tau c-(1-\tau) \bar{c}$ is the voucher received by such an individual, and $\Delta=\iint_{\Omega_{h}^{s}}[\tau c-(1-\tau) \bar{c}] \phi(a, c) d a d c$ is the net subsidy to education.

Proposition 9 The optimal policy under the Hosios Condition

Let $\beta=1-\alpha_{h}=1-\alpha_{l}=1-\alpha$. Then,

$$
\Delta=\iint_{\Omega_{h}^{s}}[\tau c-(1-\tau) \bar{c}] \phi(a, c) d a d c<0
$$

Hence, the optimal policy is to make individuals pay more on average than they would pay in the laissez-faire economy. This result generalizes Charlot and Decreuse (2005). When agents have the same schooling cost, they do not self-select enough on the basis of ability. The optimal education policy is to set a tax on education to deter too low ability agents from entering the educated sector. This result survives the consideration of schooling cost heterogeneity and the need to subsidize the education of high schooling cost and high ability individuals.

\section{Conclusion}

This paper studies the efficiency of educational choices in a two sector/two schooling level matching model of the labour market where a continuum of heterogenous workers allocates itself between sectors depending on their decision to invest in education. Individuals differ in ability and schooling cost, the search market is segmented by education, and there is free entry of new firms in each sector. Self-selection in education originates composition effects in the distribution of skills across sectors, as the distribution of ability among those who get an education differs from the distribution of ability in the whole population. This in turn modifies the intensity of job creation, implying the private and social returns to schooling always differ. Provided that ability and schooling cost are not too positively correlated, agents with large schooling costs - the 'poor' - select themselves too much, while there is too little self-selection among the low schooling cost individuals - the 'rich'. Efficiency can be restored by a combination of education and labour market policy involving three instruments: first, a sector-specific tax on output to compensate inadequate bargaining power; second, a lump-sum tuition cost to deter the low abilitylow schooling cost from schooling; third, a subsidy increasing in private schooling costs to encourage more talented individuals with large schooling costs to get an education. In 
addition, we show that education must be more taxed than subsidized in the case where the Hosios condition holds. 


\section{APPENDIX}

\section{A. Proofs}

Proof of proposition 1 In text.

Proof of proposition 2 We proceed in five steps. We start by the free entry equations (4.6) determining sector-specific tightnesses.

Step 1. (i) At given $\bar{a}_{i}>0$, there exists a unique $\theta_{i} \equiv \Theta_{i}\left(\bar{a}_{i}\right)$ solving (4.6), $i=h, l$. (ii) $\Theta_{i}$ is strictly increasing, with $\lim _{a \rightarrow 0} \Theta_{i}(a)=0$ and $\lim _{a \rightarrow \infty} \Theta_{i}(a)=\infty$.

(iii) $\Theta_{h}\left(\bar{a}_{h}\right)>\Theta_{l}\left(\bar{a}_{l}\right)$ iff $A_{h} \bar{a}_{h}>A_{l} \bar{a}_{l}$

Proof. (i) Existence and uniqueness follow from Assumption 3. Claim (ii) results from the implicit function theorem, the fact the matching function satisfies the Inada conditions, and from its boundary properties. Claim (iii) follows directly from equations (4.6), $i=h, l$.

We now consider the schooling return, rewritten here for convenience:

$$
R \equiv \Re\left(\theta_{l}, \theta_{h}\right)=\frac{\beta \mu\left(\theta_{h}\right)}{\delta+\beta \mu\left(\theta_{h}\right)} \frac{A_{h}}{\delta}-\frac{\beta \mu\left(\theta_{l}\right)}{\delta+\beta \mu\left(\theta_{l}\right)} \frac{A_{l}}{\delta}
$$

Step 2. (i) The function $\Re$ is strictly decreasing in $\theta_{l}$ and strictly increasing in $\theta_{h}$

(ii) $\Re\left(\theta_{l}, \theta_{h}\right) \in\left[-A_{l} / \delta, A_{h} / \delta\right]$

(iii) $\Re\left(\theta_{l}, \theta_{h}\right)>0$ if $\theta_{h} \geq \theta_{l}$

Proof. (i) follows from the fact that the function $\mu$ is strictly increasing in $\theta_{i}$. Claim (ii) results from the boundary properties of the function $\mu$. Claim (iii) is induced by $A_{h}>A_{l}$.

Step 3. An interior equilibrium solves

$$
\begin{aligned}
& \bar{a}_{l}^{*}=\mathbb{E}\left[a \mid c>\Re\left(\Theta_{l}\left(\bar{a}_{l}^{*}\right), \Theta_{h}\left(\bar{a}_{h}^{*}\right)\right) a\right] \\
& \bar{a}_{h}^{*}=\mathbb{E}\left[a \mid c \leq \Re\left(\Theta_{l}\left(\bar{a}_{l}^{*}\right), \Theta_{h}\left(\bar{a}_{h}^{*}\right)\right) a\right]
\end{aligned}
$$

with $\theta_{i}^{*}=\Theta_{i}\left(\bar{a}_{i}^{*}\right), i=h, l$, and $\Re\left(\Theta_{l}\left(\bar{a}_{l}^{*}\right), \Theta_{h}\left(\bar{a}_{h}^{*}\right)\right)>0$

Proof. This is implied by definition 1 , step 1 and step 2 .

We now proceed to solve the fixed point problem stated by equation (A.2) and (A.3). To this aim, let us define the function $\Psi: \mathbb{R}_{+} \times \mathbb{R}_{+} \rightarrow \mathbb{R}_{+} \times \mathbb{R}_{+}$such that $\Psi\left(a_{l}, a_{h}\right)=\left(\Psi_{h}\left(a_{l}, a_{h}\right), \Psi_{l}\left(a_{l}, a_{h}\right)\right)$, where

$$
\begin{aligned}
\Psi_{l}\left(a_{l}, a_{h}\right) & =\mathbb{E}\left[a \mid c>\Re\left(\Theta_{l}\left(a_{l}\right), \Theta_{h}\left(a_{h}\right)\right) a\right] \\
\Psi_{h}\left(a_{l}, a_{h}\right) & =\mathbb{E}\left[a \mid c \leq \Re\left(\Theta_{l}\left(a_{l}\right), \Theta_{h}\left(a_{h}\right)\right) a\right]
\end{aligned}
$$


Step 4. Let $a_{\max }=\max _{R \in\left[0, A_{h} / \delta\right]} \mathbb{E}[a \mid c \leq R a]$ and $\Lambda=[0, \mathbb{E}(a)] \times\left[\mathbb{E}(a), a_{\max }\right]$. Under Assumption 3, $\Psi(\Lambda) \subset \Lambda$

Proof. Take any pair $\left(a_{l}, a_{h}\right) \in \Lambda$. As $a_{h} \geq a_{l}$, step 1 implies $\Theta_{h}\left(a_{h}\right)>\Theta_{l}\left(a_{l}\right)$. Then, $\Re\left(\Theta_{l}\left(a_{l}\right), \Theta_{h}\left(a_{h}\right)\right)>0$ from step 2. Assumption 3 and the definition of $a_{\max }$ imply

$$
a_{\max } \geq \mathbb{E}\left[a \mid c \leq \Re\left(\Theta_{l}\left(a_{l}\right), \Theta_{h}\left(a_{h}\right)\right) a\right]>\mathbb{E}(a)
$$

But, for all $b>0$,

$$
x_{h} \mathbb{E}[a \mid c \leq b a]+\left(1-x_{h}\right) \mathbb{E}[a \mid c>b a]=\mathbb{E}(a)
$$

where

$$
x_{h}=\int_{a} \int_{c \leq b a} \phi(a, c) d c d a<1
$$

Therefore, Assumption 3 also implies

$$
0<\mathbb{E}\left[a \mid c>\Re\left(\Theta_{l}\left(a_{l}\right), \Theta_{h}\left(a_{h}\right)\right) a\right]<\mathbb{E}(a)
$$

It follows from inequalities (A.6) and (A.9) that $\Psi\left(a_{l}, a_{h}\right) \in \Lambda$, which establishes the claim.

Step 5. (conclusion) There exists an interior equilibrium with $\bar{a}_{l}^{*}<\mathbb{E}(a)<\bar{a}_{h}^{*}$

Proof. The set $\Lambda$ is compact and the function $\Psi$ is continuous. From the fixedpoint theorem, there exists $\left(\bar{a}_{l}^{*}, \bar{a}_{h}^{*}\right) \in \Lambda$ such that $\left(\bar{a}_{l}^{*}, \bar{a}_{h}^{*}\right)=\Psi\left(\bar{a}_{l}^{*}, \bar{a}_{h}^{*}\right)$. To close the proof, note that inequalities (A.6) and (A.9) hold for all $\left(a_{l}, a_{h}\right) \in \Lambda$. Therefore, $\bar{a}_{l}^{*}<\mathbb{E}(a)<\bar{a}_{h}^{*}$.

Proof of proposition 3 We derive rigorously the planner's commands. Let $p(a, c)$ be the proportion among workers of ability $a$ and schooling cost $c-(a, c)$-workers who participate to either one of the two search markets. Let also $\pi_{i}(a, c)$ be the proportion of $(a, c)$-workers affected to the subset $\Omega_{i}$. The planner's objective writes

$$
\mathbf{S}=\max _{p, \pi_{i}, \theta_{i}}\left\langle\int_{a} \int_{c} p(a, c) \phi(a, c)\left\{\sum_{i} \pi_{i}(a, c) P_{i}(a)-\pi_{h}(a, c) c\right\} d c d a\right\rangle
$$

where $P_{i}(a)$ is given by (4.12). The maximization problem is subject to $u_{i}=$ $\mu\left(\theta_{i}\right) /\left(\delta+\mu\left(\theta_{i}\right)\right), i=h, l, p(a, c) \in[0,1]$ and $\pi_{l}(a, c)=1-\pi_{h}(a, c) \in[0,1]$.

For all $(a, c) \in \Omega$, the first-order conditions write down

$$
\begin{aligned}
p^{s}(a, c) & =1 \Leftrightarrow \sum_{i} \pi_{i}^{s}(a, c) P_{i}^{s}(a) a-\pi_{h}^{s}(a, c) c \geq 0 \\
\pi^{s}(a, c) & =1 \Leftrightarrow R^{s}(a) a=\left[P_{h}^{s}(a)-P_{l}^{s}(a)\right] a \geq c \\
\frac{\gamma}{\eta\left(\theta_{i}^{s}\right)} & =\alpha\left(\theta_{i}^{s}\right) \frac{A_{i} \bar{a}_{i}^{s}}{\delta+\mu\left(\theta_{i}^{s}\right)}, i=h, l
\end{aligned}
$$


with

$$
\bar{a}_{i}^{s}=\frac{\int_{a} \int_{c} \phi(a, c) \pi_{i}^{s}(a, c) p^{s}(a, c) a d a d c}{\int_{a} \int_{c} \phi(a, c) \pi_{i}^{s}(a, c) p^{s}(a, c) d a d c}
$$

Note that we impose $p^{s}(a, c)=1$ when (A.11) holds with equality. Similarly, $\pi_{h}^{s}(a, c)=1$ when $R^{s}(a) a=c$. We can do so as the joint distribution over $a$ and $c$ has no mass point by assumption.

Proof of proposition 4 We first prove the conditions are necessary, and then that they are sufficient.

Step 1. The 'only if' part of the proof.

Assume $\bar{a}_{h}^{s}>\bar{a}_{l}^{s}$.

(i) Note first that

$$
\begin{aligned}
d R^{s}(a) / d a & >0 \text { iff }\left(1-u_{h}^{s}\right) \frac{\gamma}{\eta_{h}^{s}}>\left(1-u_{l}^{s}\right) \frac{\gamma}{\eta_{l}^{s}} \\
d\left(R^{s}(a) a\right) / d a & >0 \text { iff }\left(1-u_{h}^{s}\right) A_{h}>\left(1-u_{l}^{s}\right) A_{l}
\end{aligned}
$$

It follows from (A.13) and $\bar{a}_{h}^{s}>\bar{a}_{l}^{s}$ that $\theta_{h}^{s}>\theta_{l}^{s}$. In turn, this implies $u_{h}^{s}<u_{l}^{s}$ and $\gamma / \eta\left(\theta_{h}^{s}\right)>\gamma / \eta\left(\theta_{l}^{s}\right)$. Hence (i) is true.

(ii) Assume $P_{l}^{s}(a)<0$. This implies $a<\frac{\delta}{A_{l}} \frac{\gamma}{\eta_{l}^{s}} \equiv a_{0}$. Since $R^{s}$ is strictly increasing,

$$
R^{s}(a)<R^{s}\left(a_{0}\right)=\left(1-u_{h}^{s}\right)\left[\frac{A_{h}}{\delta}-\frac{A_{l}}{\delta} \frac{\gamma / \eta_{h}^{s}}{\gamma / \eta_{l}^{s}}\right]
$$

But $\bar{a}_{h}^{s}>\bar{a}_{l}^{s}$ implies $A_{l} \gamma / \eta_{h}^{s}>A_{h} \gamma / \eta_{l}^{s}$. It follows $R^{s}(a)<0$, and (ii) holds.

Step 2. The 'if' part of the proof.

(i) and (ii) characterize the allocation depicted by Figure 4.1. We have to show this allocation implies $\bar{a}_{h}^{s}>\bar{a}_{l}^{s}$. But,

$$
\begin{aligned}
& \bar{a}_{l}^{s}=\mathbb{E}\left[a \mid c>R^{s}(a), a \geq a_{0}\right] \\
& \bar{a}_{h}^{s}=\mathbb{E}\left[a \mid c \leq R^{s}(a)\right]=\mathbb{E}\left[a \mid c \leq R^{s}(a), a \geq a_{0}\right]
\end{aligned}
$$

For a reason similar to the one exposed in Step 4 of the proof of proposition 2, Assumption 3 implies

$$
\mathbb{E}\left[a \mid c>R^{s}(a), a \geq a_{0}\right]<\mathbb{E}\left[a \mid a \geq a_{0}\right]<\mathbb{E}\left[a \mid c \leq R^{s}(a), a \geq a_{0}\right]
$$

This closes the proof. 
Proof of proposition 5 Let $\Theta_{i}(a) \equiv \Theta\left(\beta, A_{i} a\right)$ and $u_{i} \equiv \delta /\left(\delta+\mu\left(\Theta\left(\beta, A_{i} a_{i}\right)\right)\right)$ to highlight the dependence vis-à-vis $\beta$ and $A_{i}$. The function $\Theta$ is strictly increasing in its second argument from 0 to infinity. Therefore, $\left(1-u_{i}\right) A_{i}$ and $\left(1-u_{i}\right) \gamma / \eta\left(\Theta\left(\beta, A_{i} a\right)\right)$ go from 0 to infinity with $A_{i}$ provided $a_{i}>0$. Hence as far as $\bar{a}_{h}^{s}>0, R^{s}(a)$ and $R^{s}(a) a$ are both strictly increasing in $a$ provided $A_{h}$ is sufficiently large. In addition, $R^{s}\left(a_{0}\right)>0$ if $A_{h}$ is sufficiently large. Thus, $R^{s}(a) \geq 0$ implies $P_{l}^{s}(a) \geq 0$. From Proposition $4, \bar{a}_{h}^{s}>\bar{a}_{l}^{s}$. Now, we have to prove $\bar{a}_{h}^{s}=0$ cannot be a solution to the maximization program. The (marginal) contribution of workers whose ability is close to $a_{0}$ and schooling cost close to 0 is worth $\phi\left(a_{0}\right) P_{h}^{s}\left(a_{0}\right) a_{0}>0$ if assigned to the pool of educated workers. This closes the proof.

Proof of proposition 6 We know from Proposition 4 that $R^{s}$ is strictly increasing in a. Therefore, we simply have to show that $R^{s}(0)<0$. As $\left(1-u_{h}\right) \gamma / \eta\left(\theta_{h}\right)>$ $\left(1-u_{l}\right) \gamma / \eta\left(\theta_{l}\right)$, we have $\lim _{a \rightarrow 0} R^{s}(a)=-\infty$.

Proof of proposition 7 The result is obvious from Figures 4.3 and 4.4. At given schooling cost $c$, there is over-education since the decentralized indifference line is below the efficient one. If $R^{s}(a)<R^{*}$ for all $a \geq 0$, the two curves never cross and (ii) holds. If $R^{s}(a) \geq R^{*}$ for all $a \geq a_{\lim }$, the two curves intersect in $\left(a_{\lim }, c_{\lim }\right)$. (i) follows.

Proof of proposition 8 The policy is obtained by making the centralized and decentralized allocations coincide.

Proof of proposition 9 In the remaining of the proof, let us denote $P_{i} \equiv P_{i}^{s}\left(\bar{a}_{i}^{s}\right)$. If $\beta=1-\alpha_{i}, i=h, l$, then $t_{i}=0$ and (5.1) and (5.2) hold. Hence,

$$
\begin{aligned}
\frac{1-\tau}{\tau} \bar{c} & =\frac{P_{h}-P_{l}}{u_{h} P_{h}-u_{l} P_{l}}\left[u_{h} P_{h} \bar{a}_{h}-u_{l} P_{l} \bar{a}_{l}\right] \\
& >\left[P_{h}-P_{l}\right] \bar{a}_{h} \equiv R^{s}\left(\bar{a}_{h}\right) \bar{a}_{h}
\end{aligned}
$$

Therefore,

$$
\Delta<\tau \iint_{\Omega_{h}^{s}}\left[c-R^{s}\left(\bar{a}_{h}\right) \bar{a}_{h}\right] \phi(a, c) d a d c
$$

From the f.o.c, $(a, c) \in \Omega_{h}^{s}$ iff

$$
c \leq R^{s}(a) a=\left(P_{h}-P_{l}\right) a+\frac{\alpha}{1-\alpha}\left[u_{h} P_{h}\left(a-\bar{a}_{h}\right)-u_{l} P_{l}\left(a-\bar{a}_{l}\right)\right]
$$

Integrating over $\Omega_{h}^{s}$ both sides of the inequality yields

$$
\iint_{\Omega_{h}^{s}} c \phi(a, c) d c d a<\iint_{\Omega_{h}^{s}}\left(P_{h}-P_{l}\right) a \phi(a, c) d c d a-\iint_{\Omega_{h}^{s}} \frac{\alpha}{1-\alpha} u_{l} P_{l}\left(a-\bar{a}_{l}\right) \phi(a, c) d c d a
$$

The result follows. 


\section{References}

[1] Abowd, J., Kramarz, F., Margolis, R., 1999. High wage workers and high wage firms. Econometrica 67, 251-333

[2] Acemoglu, D.T., 1996. A microfoundation for social increasing returns to human capital accumulation. Quarterly Journal of Economics 61, 779-804

[3] Arrow, K., 1973. Higher education as a filter. Journal of Public Economics 2, 193-216

[4] Burdett, K., Smith, E., 2002. The low skill trap. European Economic Review 46, $1439-1451$

[5] Cameron, S., Heckman, J.J., 2001. The dynamics of educational attainment for black, hispanic and white males. Journal of Political Economy 109, 455-499

[6] Carneiro, P., Heckman, J.J., 2001. The evidence on credit constraints in postsecondary schooling. Economic Journal 112, 705-734

[7] Charlot, O., Decreuse, B., 2005. Self-selection in education with matching frictions. Labour Economics 12, 251-267

[8] Charlot, O., Decreuse, B., Granier, P., 2005. Adaptability, productivity, and the returns to schooling in a matching model. European Economic Review 49, 1007-1032

[9] Fershtman, C., Murphy, K.M., Weiss, Y., 1996. Social status, education and growth. Journal of Political Economy 104, 108-132

[10] Fernandez, R., 2001. Sorting, education and inequality. In Advances in economic theory, Dewatripont, M., Hansen, G., Turnovsky, S., eds, Cambridge University Press

[11] Heckman, J.J., 2000. Policies to foster human capital. Research in Economics 54, $3-56$

[12] Hosios, A., 1990. On the efficiency of matching and related models of search and unemployment. Review of Economic Studies 57, 279-298

[13] Inderst, R., 2005. Competitive search markets with heterogeneous workers. European Economic Review 49, 1525-1542

[14] Laing, D., Palivos, T., Wang, P., 1995. Learning, matching and growth. Review of Economic Studies 62, 115-129 
[15] Lang, K., Manove, M., 2003. Wage annoucements with a continuum of worker types. Annales d'Economie et de Statistique 71-72, 223 - 244

[16] Moen, E.R., 1999. Education, ranking, and competition for jobs. Journal of Labor Economics 17, 694-723

[17] Moscarini, G., 2001. Excess worker reallocation. Review of Economic Studies 68, 593-612

[18] Pissarides, C., 2000. Equilibrium unemployment theory. MIT Press

[19] Roy, A., 1951. Some thoughts on the distribution of earnings. Oxford Economic Papers 3, 135-146

[20] Saint-Paul, G., 1996. Dual labor market: a macroeconomic perspective. MIT Press

[21] Snower, D., 1995. The low-skill, bad-job trap. In Acquiring skills: market failures, their symptoms and policy responses. A. Booth and D. Snower, eds. Cambridge, MA, Cambridge University Press

[22] Spence, M., 1973. Job market signalling. Quarterly Journal of Economics 87, 355-374 